\title{
The Effects of Light, Temperature, After-ripening, Nitrate and Water on Chenopodium Album Seed Germination
}

\author{
Lindsey M. Altenhofen, Jack Dekker* \\ Weed Biology Laboratory, Department of Agronomy, Iowa State University, Ames, Iowa 50011, USA \\ *Corresponding Author: jdekker@iastate.edu
}

Copyright (C) 2014 Horizon Research Publishing All rights reserved.

\begin{abstract}
Chenopodium album is a widespread and troublesome weed in Iowa and agricultural areas throughout the north temperate regions of the world. This study investigated the effects of various factors on the stimulation of germination of two populations of C. album seeds collected in 2007 and 2008 at a common location. These factors included light, temperature, after-ripening time, nitrate, and water level. Germination of both populations was generally stimulated by light, warm $\left(15-25^{\circ} \mathrm{C}\right)$ and hot $\left(25-35^{\circ} \mathrm{C}\right)$ temperatures, $0.01 \mathrm{M}$ nitrate, 3 to 5 weeks of after-ripening $\left(4^{\circ} \mathrm{C}\right.$, dark, moist), and with the 2008 population, 1.0 and $1.25 \mathrm{ml}$ of water. The interaction of these factors, particularly light, warm temperatures and nitrate, stimulated higher germination than when applied individually. Germination was very low in cold $\left(5-15^{\circ} \mathrm{C}\right)$ temperatures or darkness, regardless of other treatments applied. The goal of this experiment was to lay a foundation with two local Iowa populations to guide further studies developing a seed germination assay to determine variability of dormancy among individual seeds of and between populations. Insights about dormancy variability in C. album gained from the current research included positive responses by both populations to light, warm and hot temperatures, nitrate, and intermediate after-ripening times. However, the populations differed in their response to water quantity and, for most conditions; the 2008 population achieved greater overall germination. The overarching goal of this project is to build a condensed $C$. album seed germination assay to characterize individual populations to predict seedling emergence patterns in agricultural soils in an effort to decrease interference with crop productivity.
\end{abstract}

Keywords Seed Germination, Seed Dormancy, Chenopodium Album

\section{Introduction}

Chenopodium album (common lambsquarters) is a widespread and troublesome weed in Iowa and agricultural areas throughout the north temperate regions of the world. A considerable number of studies have been published characterizing the seed germination of $C$. album. Seed germination and seedling emergence from the soil seed pool is a critical threshold life history event immediately preceding assembly in agricultural communities and subsequent interference with crop productivity. The effects of light, temperature, after-ripening, nitrate and moisture level on the germination of C. album are reviewed herein.

\subsection{Light}

Light has been shown to increase germination of Chenopodium album (Baskin and Baskin, 1977;Cumming, 1963; Henson, 1970; Jursik et al., 2003;Karssen, 1967; Moravcova and Dostalek, 1989; Vincent and Roberts, 1977; Roberts and Benjamin, 1979; Wentland, 1965),particularly in combination with nitrate (Bouwmeester and Karssen, 1989, 1993; Henson, 1970;Moravcova and Dostalek, 1989; Roberts and Benjamin, 1979; Wentland, 1965). A light and nitrate interaction is also noticeable when studying the seeds whose parent plants were exposed to nitrate (Saini, Bassi and Spencer, 1985b).However, a few studies such as Williams (1962), have reported no significant difference in germination rates between seeds germinated in the light and in the dark.

Karssen (1967) found that responsiveness to a single red irradiation at $23^{\circ} \mathrm{C}$ following imbibition in darkness increased germination with increasing pre-irradiation time up to hour 16 (90\% germination). In a second study by Karssen (1970), the ideal interval between imbibition and irradiation was 24 hours at $23^{\circ} \mathrm{C}$ and 48 hours at $4^{\circ} \mathrm{C}$. Interestingly, imbibed seed exposed to light and subsequently dried, retain light-induced changes (Henson, 1970).

\section{Parent Plant Photoperiod}

C. album response to photoperiod length has been studied intensely at the level of the parent plant and in seed germination tests. Parent plants exposed to long photo periods (16-17 hours) produce a higher percentage of dormant seeds (Jursik et al., 2003;Wentland, 1965) as well as more seeds overall (Wentland, 1965) than plants exposed to 
8 hour photoperiods. Parent plants exposed to long photoperiods produce seeds which require light to germinate and which are stimulated by red or white light and inhibited by far red light. Seeds produced under short days do not require light to germinate and are unaffected by red or far red light (Wentland, 1965). In a unique study, Wentland (1965) found that it is the length of photoperiod and not the intensity of light experienced by the parent plant which determines the dormancy of seeds.

\section{Seed photoperiod}

Seeds germinated under long photoperiods or continuous light have lower germination rates compared to seeds germinated under short photoperiods (Cumming, 1959), reportedly taking four times as long to reach $50 \%$ germination (Wentland, 1965). This trend of decreasing germination with increasing photoperiod has also been noted in combination with nitrate (Henson, 1970), incandescent lighting (Cumming, 1963)and restricted water supply (Cumming, 1963).Traditional photoperiods are not necessary to produce high rates of germination. Exposure to15-16 minutes of light once (with nitrate, Henson, 1970) or twice (Bouwmeester and Karssen, 1989, 1993) can be sufficient to obtain high rates of germination. As little as 15 seconds of light was sufficient for older seed at $23^{\circ} \mathrm{C}$ in a study performed by Henson (1970).Regardless of short or long day germination, seeds germinate at higher percentages in the light when the perianth has been removed (Wentland, 1965).

The timing of imbibition, light exposure and nitrate application plays a large role in germination rates (Karssen, 1967).Henson (1970) discovered that when 16 minute of light was supplied 36 hours following imbibition, the interval between nitrate application and light exposure determined the germination percentage. The highest germination (about $60 \%$ ) occurred when nitrate was applied from the start of imbibition ( 36 hour interval between nitrate and light exposure). In the same study, seeds imbibed with nitrate but not exposed to light only reached about $5 \%$ germination. Furthermore, seeds imbibed in darkness for extended amounts of time subsequently required more light energy to stimulate germination (Henson, 1970).

\section{Light X Temperature}

There is a noted interaction between light and temperature, with higher rates of germination typically seen with alternating as opposed to constant temperatures in the light (Henson, 1970; Moravcova and Dostalek, 1989;Murdoch, Roberts and Goedert, 1989). Vincent and Roberts (1977) found that light, in combination with alternating temperatures, has a more significant effect when the warmer temperature is maintained for 16 hours rather than 8 hours. Henson (1970) reported that alternating temperatures with a $20^{\circ} \mathrm{C}$ difference increased germination to over $40 \%$ whereas a variation of $10^{\circ} \mathrm{C}$ resulted in only about $5 \%$ germination.

Light X Temperature X Nitrate
Light, temperature and nitrate interact strongly as characterized by Henson (1970),Moravcova and Dostalek (1989), Vincent and Roberts (1977) and Roberts and Benjamin (1979) (with extended after-ripening time).Henson (1970) found that treatments with light plus nitrate had twice the germination at $23^{\circ} \mathrm{C}$ than seen at either $10^{\circ} \mathrm{C}$ or $30^{\circ} \mathrm{C}$, and greater germination than any treatment of light or nitrate applied separately at 10,23 , or $30^{\circ} \mathrm{C}$.

\subsection{Nitrate}

Application of nitrate to agricultural soils and in the lab have been shown to stimulate the germination of C. album seeds (Bouwmeester and Karssen, 1989, 1993;Fawcett and Slife, 1978;Henson, 1970;Moravcova and Dostalek, 1989;Saini, Bassi and Spencer, 1985a, 1986;Williams, 1962, 1963; Williams and Harper, 1965;Wentland, 1965;Vincent and Roberts, 1977; Roberts and Benjamin, 1979). Endogenous nitrate concentration in seed is directly related to the parent plant's exposure to exogenous nitrate (Fawcett and Slife, 1978;Saini, Bassi and Spencer, 1985b) or exogenous nitrate applied directly to seed (Williams, 1962). Heteromorphic seed from the same parent plant has been shown to contain different endogenous nitrate levels, with brown seed having a higher average endogenous nitrate concentration than black seed(Williams 1962, 1963).Nitrate application to the parent plant also increases seed production but it does not alter the ratio of brown to black seed produced (Williams, 1962).

Exposure of seeds to exogenous nitrate can result in significantly higher germination within 4 days of application compared to germination with non-supplemented seed (Saini, Bassi and Spencer, 1985a).The parent plant's history of exposure to nitrate can affect how seeds are subsequently stimulated to germinate. Application of exogenous nitrate to seeds from nitrogen-deficient parent plants resulted in lower germination rates compared to seeds produced by nitrogen-rich parent plants (Fawcett and Slife, 1978). The interaction between light, nitrate and age of seed may also be significant. In a study by Henson (1970), nearly all young seed required a combination of light plus neither nitrate to germinate, whereas $30 \%$ of older seed was able to germinate with neither light nor nitrate.

Light and nitrate have a stimulatory effect on C. album seed germination but nitrate alone can be stimulatory. Saini, Bassi and Spencer (1985a) reported higher rates of germination in the dark when seeds were exposed to nitrate. Bouwmeester and Karssen $(1989,1993)$ found the same trend, although slight, which became more pronounced in combination with desiccation of seeds.

\section{Nitrate X Temperature}

Higher germination rates have been reported in the dark with nitrate at alternating temperature regimes as opposed to with nitrate at constant temperatures(Vincent and Roberts, 1977; Saini, Bassi and Spencer, 1986). 


\section{Nitrate X After-Ripening Time}

Moravcova and Dostalek (1989) showed increased germination when nitrate was supplied to seed in combination with pre-chilling (after-ripening) treatments. Similarly, Williams $(1962,1963)$ found that increased endogenous nitrate levels coincide with longer pre-chilling periods.

Response to nitrate and pre-chilling treatments may be specific to seed morphs. Williams and Harper (1965) reported that brown-reticulate and brown-smooth seed have $>90 \%$ germination without after-ripening $\left(\right.$ at $5^{\circ} \mathrm{C}$ ) or nitrate application while black-reticulate seed show no increase in germination from after-ripening, but do increase germination from 63 to $90 \%$ with the addition of nitrate. Black-smooth seed increase germination from 32 to $61 \%$ with after-ripening alone, and increase germination from 32 to $94-95 \%$ with nitrate (with or without after-ripening). These findings indicate that after-ripening can partially substitute for lack of nitrate, particularly in black-smooth seed.

\section{Nitrate Concentration}

Potassium nitrate is commonly used as the source of nitrate for C. album experiments in the lab, varying in concentration from 0.0001 to $.309 \mathrm{M}$ (Saini, Bassi and Spencer, 1985a; Henson, 1970). Highly stimulatory $\mathrm{KNO}_{3}$ concentrations have been reported as 0.1 M (Henson, 1970; Saini, Bassi and Spencer, 1985a), 0.01 M (Saini, Bassi and Spencer, 1985a), 0.001 M (Williams and Harper, 1965), and $.0001 \mathrm{M}$ (Williams, 1962). For example, a $0.1 \mathrm{M} \mathrm{KNO}_{3}$ solution increased germination of C. album seeds from $32.5 \%$ (distilled water) to $89.3 \%$ (Williams and Harper, 1965). High concentrations of nitrate such as $0.309 \mathrm{M}$ were not found to be stimulatory (Henson, 1970).

\subsection{After-ripening}

After-ripening (AR) is generally defined as any conditioning a seed undergoes post-abscission and is often synonymous with pre-chilling or storage at low temperatures in moist conditions in the dark.AR has been shown to stimulate germination in C. album, particularly in combination with light and nitrate (Moravcova and Dostalek, 1989; Williams, 1962, 1963;Williams and Harper, 1965; Roberts and Benjamin, 1979;Vincent and Roberts, 1977). However, AR has little effect when seeds are subsequently germinated in the dark with no nitrate at constant temperatures (Moravcova and Dostalek, 1989).Williams and Harper (1965) concluded that AR temperatures of $-5,0$, and $+5^{\circ} \mathrm{C}$ were equally effective on both wet and dry seed.

With 3 weeks of exposure to $5^{\circ} \mathrm{C}$ temperatures, Williams and Harper (1965) demonstrated that seeds can increase germination percentage from about 30 (no after-ripening) to $65 \%$. Roberts and Benjamin (1979) reported that seeds exposed to constant $30^{\circ} \mathrm{C}$ conditions in the light reached maximum germination of around $25 \%$ when after-ripened for 4 days at $4{ }^{\circ} \mathrm{C}$. Comparatively, seeds not after-ripened and kept at a constant $30^{\circ} \mathrm{C}$ in the light had $0 \%$ germination.

Williams (1963) reported that after-ripening for 3 to 4 weeks is required, in combination with other stimulatory treatments, to maximize germination. Roberts and Benjamin (1979), however, reported the "best chilling treatment" to be 4 days at $4^{\circ} \mathrm{C}$, in the dark, without nitrate. Extended AR may result in reduced germination and possibly induction of secondary dormancy (Roberts and Benjamin, 1979), although Williams (1962) found that seeds tested after 12 or 52 weeks of after-ripening showed the same germination percentage as after 4 weeks of after-ripening. Roberts and Benjamin (1979) found that after-ripening in the dark results in the ability to better respond to light and nitrate interaction than after-ripening in the light.

\subsection{Moisture Level}

In the majority of published C. album studies, response to moisture level has not been investigated and thus was not quantified or reported. Typically, studies have been carried out on filter paper in petri dishes which are rewetted as needed throughout the experiment. Dry seeds are considered to be insensitive to stimulation by light, although imbibed seeds exposed to light and subsequently dried, retain light-induced changes (Henson, 1970). A combination of continuous light and restricted water ( $0.5 \mathrm{ml}$ compared to 1.0 $\mathrm{ml}$ ) inhibited germination as reported by Cumming (1963) in both incandescent and (less so) fluorescent lighting. Bouwmeester and Karssen (1989) reported slightly higher rates of germination from seeds which were desiccated following burial in soil and prior to germination treatments in the light and dark, with nitrate. Chu, Sweet and Ozbun (1978) reported that seeds soaked in running tap water germinated at a higher percentage than unsoaked seed. However, Wentland (1965) found that washing seed for up to 96 hours had no effect on germination at 8 or 17 hour photoperiods.

\subsection{Temperature}

Constant and alternating temperature regimes interact with light and nitrate in complex patterns. Optimal constant temperature for germination of C. album in the light is typically considered to be between 15 and $25^{\circ} \mathrm{C}$ (Baskin and Baskin, 1977;Harvey and Forcella, 1993;Henson, 1970; Jursik et al., 2003; Cumming, 1959; Williams, 1962). Alternating temperatures in the light have been reported optimal at $20-30^{\circ} \mathrm{C}$ (Cumming, 1959) or $10-30^{\circ} \mathrm{C}$ (Henson, 1970 ) and with greater than $25 \%$ germination at $15-25,15-30$, and $20-35^{\circ} \mathrm{C}$ following 4 weeks of burial (Baskin and Baskin, 1987).Optimal constant temperature in the dark has been reported at $20^{\circ} \mathrm{C}$ and alternating $10-20^{\circ} \mathrm{C}$ (Cumming, 1959).Typically, there is no germination below $4-6^{\circ} \mathrm{C}$ (Harvey and Forcella, 1993; Jursik et al., 2003; Wiese and Binning, 1987) and limited germination above $30^{\circ} \mathrm{C}$ (Jursik et al., 2003). However, Williams and Harper (1965) reported 
that brown seed is capable of germination at $0^{\circ} \mathrm{C}$ with water. Henson (1970) hypothesized that high temperatures may induce thermo-dormancy, in effect reducing seed response to favorable temperatures.

\section{Constant and Alternating Temperatures}

Seeds exposed to light without nitrate and to nitrate without light saw high germination rates at alternating temperatures of $10-30^{\circ} \mathrm{C}\left(20^{\circ}\right.$ difference $)$ but not when exposed to alternating temperatures of $15-25^{\circ} \mathrm{C}\left(10^{\circ}\right.$ difference) (Henson, 1970). The highest germination reported by Moravcova and Dostalek (1989) involved a combination of light, nitrate, alternating temperatures, and after-ripening. Even with no after-ripening, alternating temperatures $\left(10-30^{\circ} \mathrm{C}\right)$ produced a larger germination response with light, nitrate or light plus nitrate treatments compared to the same treatments under constant $25^{\circ} \mathrm{C}$.A similar positive interaction occurred among light, nitrate, alternating temperatures and AR as reported by Vincent and Roberts (1977).

\section{Seed Heteroblasty and Phytochrome}

Seed heteroblasty is the variable dormancy-germinability capacity among individual seeds shed by a single parent plant at abscission. Heteroblasty is induced in the seed at the time of embryogenesis by the parent plant and is retained for the life of the seed. This original dormancy-germinability state changes with life history and annual cycling in the soil seed pool. The underlying mechanisms controlling this dynamic state in seeds may be due to the presence of multiple-interacting phytochromes modulating seed behaviors. Further analysis of the phytochrome system is outside the scope of this paper but has been published in several papers (Holmes and Smith, 1975, 1977abc; Morgan and Smith, 1978, 1979, 1981; Smith, 2000; Smith and Whitelam, 1997; Smith, Casal and Jackson, 1990).

From this literature review, several deficits are evident in our understanding of Chenopodium album germination. For example, the history of seed prior to experimentation may have an effect on the germinability of seed, but this information is often incomplete or missing in published research. A complete seed history should include the following:a) the date of harvest, b) the ecological description of the population habitat, c) seed harvest and storage preparation description,d) storage condition and e) duration of storage pre-experiment. Of these necessary pieces of information, only $4 \%$ of the 24 common lambsquarters germination studies reviewed herein included all five details, $29 \%$ included four, $25 \%$ included three, $25 \%$ included two, and $17 \%$ included only one or no details of the seed history. This lack of seed history information seriously compromises the repeatability, comparability and interpretation of these published studies.

Another gap in our understanding of C. album germination comes from the limited number of parameters(e.g. light, temperature, after-ripening, nitrate, and water) which have been examined within any one study. Of the 24 studies focused on C. album germination reviewed here, only $12 \%$ included five or more parameters, $21 \%$ included four, $29 \%$ included three, and $38 \%$ included only one or two. Additionally, only 4 of the studies compared multiple populations of common lambsquarters.

With these limitations in our understanding of the dynamic nature of Chenopodium album seed germination, we designed a study to determine the combined effects of light, temperature, after-ripening time, nitrate and water level and their interactions. We studied two Iowa populations of $C$. album derived from a common farm in central Iowa and thoroughly detailed the seed history of each population.

\section{Methods and Materials}

\subsection{Seeds}

Seeds of two populations of Chenopodium album were used to determine the effects of light, temperature, nitrate $\left(\mathrm{KNO}_{3}\right)$, moisture level and after-ripening time $\left(\mathrm{AR} ; 4^{\circ} \mathrm{C}\right.$, dark, moist) on germination. A factorial treatment design was tested on two populations from a common location collected in consecutive years:2007 (Dekker germplasm collection lot \#3991, Weed Biology Laboratory, Iowa State University) and 2008 (Dekker germplasm collection lot \#3995, Weed Biology Laboratory, Iowa State University). The 2007 seed was harvested in the fall on October 5, 2007 from a maize field on Curtiss Farm, ISU Experimental Station, Ames, Iowa, USA. The 2008 seed was harvested in the fall on October 11, 2008 in a soybean field also located on Curtiss Farm. Seeds from both years were harvested within 245 yards of $42^{\circ} 0^{\prime} 15.37^{\prime \prime} \mathrm{N}, 93^{\circ} 40^{\prime} 4.58^{\prime \prime} \mathrm{W}$.

Immediately after harvest, 2007 and 2008 seed was passively air-dried on screens for 9 and 7 days, respectfully. The perianthand pericarp (see Seed Heteromorphy, below) remained intact on the majority of seed as collected in the field. At no point was the perianth or pericarp forcefully removed. The dried seeds were then placed in 250 to $500 \mathrm{ml}$ translucent HDPE Nalgene containers with screw-tight lids (Fisher Scientific, Pittsburgh, Pennsylvania, USA).The 2007 population was immediately placed into storage at constant temperatures of $-20,4$ or $20^{\circ} \mathrm{C}$ with very low to no light. The 2008 population was stored at a constant $20^{\circ} \mathrm{C}$ for 132 days prior to storage at $4^{\circ} \mathrm{C}$ (see Table 1). Seeds were taken from these conditions immediately prior to use in each of the experiments.

The effects of seed storage temperature and duration were accounted for as random effects in the ANOVA performed. However, a closer look at the individual replications for the 2007 population reveals possible germination effects due to storage temperature with seed stored at $20^{\circ} \mathrm{C}$ having higher germination rates than those $4^{\circ} \mathrm{C}$ which in turn had higher rates than those stored at $-20^{\circ} \mathrm{C}$. Because this storage condition effect was accounted for when constructing the 
ANOVA and therefore did not largely affect the results, storage condition will not be a primary discussion point in this paper. Differences in the duration of storage for the 2007 and 2008 populations of six and twelve weeks respectively did not have any noticeable effect on germination rates.

Table 1. Seed storage information

\begin{tabular}{|c|c|c|c|}
\hline & & \multicolumn{2}{|c|}{ Storage Condition $^{\mathrm{c}}$} \\
\hline $\begin{array}{c}\text { Population/ } \\
\text { Year Collected }\end{array}$ & Replication & Temperature & Time Stored (days) \\
\hline & 1 & $20^{\circ} \mathrm{C}$ & 502 \\
$2007^{\mathrm{a}}$ & 2 & $4^{\circ} \mathrm{C}$ & 516 \\
& 3 & $-20^{\circ} \mathrm{C}$ & 522 \\
& 4 & $-20^{\circ} \mathrm{C}$ & 530 \\
& 5 & $-20^{\circ} \mathrm{C}$ & 543 \\
\hline \multirow{5}{*}{$2008^{\text {ab }}$} & 1 & $4^{\circ} \mathrm{C}$ & 7 \\
& 2 & $4^{\circ} \mathrm{C}$ & 18 \\
& 3 & $4^{\circ} \mathrm{C}$ & 21 \\
& 4 & $4^{\circ} \mathrm{C}$ & 35 \\
& 5 & $4^{\circ} \mathrm{C}$ & 46 \\
& 7 & $4^{\circ} \mathrm{C}$ & 55 \\
& 8 & $4^{\circ} \mathrm{C}$ & 62 \\
& 9 & $4^{\circ} \mathrm{C}$ & 69 \\
& 10 & $4^{\circ} \mathrm{C}$ & 83 \\
& 7 & $4^{\circ} \mathrm{C}$ & 88 \\
\hline
\end{tabular}

${ }^{a}$ Harvested from Curtiss Farm, ISU Experimental Station, Ames, Iowa, USA.

${ }^{\mathrm{b}}$ Following harvest and drying, 2008 seeds were stored at $20^{\circ} \mathrm{C}$ for 132 days prior to storage at $4^{\circ} \mathrm{C}$.

${ }^{\mathrm{c}}$ All seeds stored dry, in translucent HDPE Nalgene containers.

\subsection{Seed Heteromorphy}

Chenopodium album germinates spring through late summer with peaks of germination in April and August (Williams, 1963). Flowers are arranged in glomerules, forming spikes at a terminal panicle (Gleason and Cronquist, 1963). Seeds appear to be disk-shaped with two convex sides. Detailed seed morphology and classification is not agreed upon in published literature, but similarities are evident among descriptions as illustrated herein.

As described by Delorit (1970), seeds of C. album are black, with a glossy surface and enclosed in a semi-translucent granular pericarp. The five-parted perianth may also be attached to the seed, but is often detached during collection and subsequent handling. The seeds of C. album have been described by Williams and Harper (1965) as having four distinct forms at maturity: brown-reticulate, brown-smooth, black-reticulate and black-smooth. Additionally, all of these seed types may be present on the same plant. Chu, Sweet and Ozbun (1978) described seed as having four color morphs: brown, deep brown, brown-black and black but they did not distinguish between smooth or reticulate. Wentland (1965) described the variation in color as yellow, orange, and dark red being characteristic of immature seed, whereas mature seeds are dark in color. A few studies considered here (Henson, 1970; Moravcova and Dostalek, 1989) stated that they used only black seed while most studies did not specify seed morphology.

The study reported herein used only seed which appeared to be brown to dark brown in color, with pericarp intact or nearly complete, as this was the state of seed when collected. A perianth was present on roughly half of seeds used, in an open or closed formation, as collected in the field. Immature, yellow, orange or red seeds were omitted from experiments.

\subsection{Germination}

Germination was evaluated in $30 \mathrm{ml}$ gas-tight vials, with $20 \mathrm{~mm}$ outside diameter mouths (Wheaton Science Products, Millville, New Jersey, USA) (as described in Dekker and Hargrove, 2002). Two disks of Anchor Blue germination blotter paper (Anchor Paper Co., St. Paul, Minnesota, USA), $32 \mathrm{~mm}$ in diameter, were placed in, and completely covered, the bottom of the vials. Following insertion of blotter paper, $0.75,1.00$, or $1.25 \mathrm{ml}$ of distilled, de-ionized water (or $\mathrm{KNO}_{3}$ solution, as described below) was added to the vials along with ten dry, mature $C$. album seeds which had been sorted under a dissecting microscope to ensure quality. After placing water solutions and seeds in the vials, they were immediately sealed with neoprene stoppers and crimped (Wheaton hand crimper, model 22430; Wheaton Science Products, Millville, New Jersey, USA) around the vial neck with an aluminum ring to ensure a gas- and watertight seal. All vials were then grouped and wrapped in two layers of aluminum foil (except light treatments with no after-ripening period). Seed to be germinated in the dark remained in foil for the entirety of the experiment. After preparation, vials were placed in either after-ripening (AR 1 to 10 weeks) or germination (AR 0 weeks) assay conditions. Vials remained sealed throughout after-ripening and the germination experiment. Each replication of 396 vials was set up individually within the span of 11 hours, starting from the time seeds were removed from storage and ending when sealed vials were moved into controlled AR or germination cabinets. All vials were prepared under normal laboratory lighting at room temperature.

\subsection{After-ripening}

Seeds of the 2007 and 2008 populations were exposed to after-ripening (AR) conditions at constant $4^{\circ} \mathrm{C}$ in the dark, while moist, for 0 to 10 weeks. Darkness was achieved by wrapping vials in two layers of aluminum foil.

\subsection{Germination Assay}

The sealed vials with germination paper, water $\left(\right.$ or $\left.\mathrm{KNO}_{3}\right)$, and seed were placed in one of three Hoffman (model SG-30, Hoffman Manufacturing, Albany, Oregon, USA) controlled environment seed germination cabinets for seven days, after which germination data was collected. Each of the three chambers alternated in twelve hour shifts between a low and high temperature: $\quad 5-15^{\circ} \mathrm{C}($ cold $), \quad 15-25^{\circ} \mathrm{C}$ (warm) and $25-35^{\circ} \mathrm{C}$ (hot)with all temperatures accurate to $\pm 1{ }^{\circ} \mathrm{C}$. In each of these chambers a dark ( $24 \mathrm{~h}$ dark: $0 \mathrm{~h}$ light; provided by a double layer of aluminum foil around the vials) or light 
(24 $\mathrm{h}$ light:0 $\mathrm{h}$ dark) regime was maintained for the duration of the study. The fluorescent lighting source was six fluorescent tubes (average $21.61 \mu \mathrm{mol} \mathrm{s}^{-1} \mathrm{~m}^{-2}$, minimum 4.02 $\mu \mathrm{mol} \mathrm{s} \mathrm{m}^{-1}$, maximum $49.90 \mu \mathrm{mol} \mathrm{s}^{-1} \mathrm{~m}^{-2}$ ). Brand of tube and assignment to cabinets was not controlled. After seven days in the germination cabinets, the number of seeds germinated was determined for each vial. Germination was evidenced by radicle protrusion outside the seed hull.

\subsection{Nitrate}

Preliminary nitrate assays showed C. album to have the highest germination at $0.01 \mathrm{M} \mathrm{KNO}_{3}$ compared to 0.0001 , $0.001,0.1$, or $0.25 \mathrm{M} \mathrm{KNO}_{3}$ with no germination occurring at or above $0.5 \mathrm{M} \mathrm{KNO}_{3}$. As such, two levels of nitrate $(0,0.01$ $\mathrm{M})$ were used in the studies reported herein.

\subsection{Moisture}

Preliminary assays showed water levels above $0.5 \mathrm{ml}$ and below $2.0 \mathrm{ml}$ stimulated germination. Levels above $2.0 \mathrm{ml}$ showed a declining germination trend as water levels increased up through $4 \mathrm{ml}$. As such, three levels of distilled water $(0.75,1.00,1.25 \mathrm{ml})$ were used in this study.

\subsection{Experimental Design and Analysis}

This study used a factorial arrangement to test all possible combinations of factors. The study included two trials:the 2007 population with five replications(a replication being 396 vials representing one of each treatment combinations) and the 2008 population with ten replications (Table 1a).The factorial arrangement of treatments consisted of two light levels ( 24 hour light, 24 hour dark), three temperature levels $\left(5-15,15-25,25-35^{\circ} \mathrm{C}\right.$; alternating at 12 hour intervals), eleven after-ripening levels $(0,1,2,3,4,5,6,7,8,9,10$ weeks at $4^{\circ} \mathrm{C}$, dark, moist), two $\mathrm{KNO}_{3}$ levels $(0,0.01 \mathrm{M})$, and three water levels $(0.75,1.0,1.25 \mathrm{ml})$. Results were recorded for each vial as the number of seeds germinated out of 10 seeds.

An ANOVA was used to test the main effects and all interactions among the five treatments for the number of seeds germinated for the 2007 and 2008 populations individually. The tests indicated which interactions were significant. The highest order interactions for each treatment were used to further assess treatment effects since higher order interactions indicate that main effects and lower order interactions for those terms do not fully describe the relationships. Thus, means and standard errors using the ANOVA mean square error were calculated for these higher order interactions. The significant ANOVA interactions reported herein included those for 2007 (light $x$ temperature $\mathrm{x}$ after-ripening time, light $\mathrm{x}$ nitrate $\mathrm{x}$ after-ripening time and light $\mathrm{x}$ temperature $\mathrm{x}$ nitrate) and 2008 (light $\mathrm{x}$ temperature $\mathrm{x}$ nitrate $\mathrm{x}$ water and light $\mathrm{x}$ temperature $\mathrm{x}$ nitrate $\mathrm{x}$ after-ripening time) populations. In addition, all pairwise treatment differences were tested using the Tukey-Kramer method which controls the Type I error rate (probability of declaring a difference significant when in fact it is not) at alpha $=.05$ for the entire family of comparisons (i.e., all means comparisons for a given interaction). All analytical procedures were performed using SAS (SAS Institute Inc, Cary, North Carolina, USA).

\section{Comparative Germination Responses between the 2007 and 2008 Populations}

\subsection{Population Similarities}

Cold temperatures and darkness always resulted in very low germination in both the 2007 and 2008 C. album populations, regardless of nitrate level, water quantity or after-ripening duration. At warm and hot temperatures in the light, addition of $0.01 \mathrm{M}$ nitrate increased germination for both populations. Germination in the light at warm and hot temperatures generally increased with after-ripening time for both populations, followed by a plateau of stimulated germination and then a decrease to levels similar to those seen with 0 weeks of after-ripening. Maximum germination occurred when light, warm temperatures, $0.01 \mathrm{M}$ nitrate and/or an intermediate duration of after-ripening was experienced. These seemed to be the optimal germination conditions of the factors studied herein and were particularly stimulatory when used in combination.

\subsection{Population Differences}

Differences between the 2007 and 2008 C. album populations were observed and many provide the hypothetical basis for future research investigating seed heteroblasty and variability in germinability among seeds of a population. These differences include both endogenous biological differences and differences in germination arising from statistical modeling.

Biological differences. Analysis of the 2007 population showed no response to the three water quantities examined while the 2008 population responded with higher germination at 1.0 and $1.25 \mathrm{ml}$ water relative to $0.75 \mathrm{ml}$. Also, maximum germination rates for most conditions were higher in the 2008 population compared to the 2007 population. Differences between the 2007 and $2008 \mathrm{C}$. album populations may be attributed to the environment experienced during the growth of the parent plant such as the availability of water and nitrate throughout the season as influenced by natural causes and agricultural practices in the immediate area. While both populations were harvested from a common field, they were separated by roughly 500 yards and temporally spaced by one year. Differential responses of the seed to water and other parameters based on seed history, such as how seed was handled and the conditions and duration of storage could also account for some 
discrepancies between the two populations although these were accounted for in the ANOVA model. Furthermore, replications for the 2007 and 2008 population were conducted over a span of 6 and 12 weeks, respectively. While this time span was not likely to have a direct effect on the seed, it may have introduced error from changes in the light intensity and other factors within each germination cabinet.

Statistical differences. The mean square error (MSE) for the 2007 and 2008 populations were 0.82 and 0.62 , respectively. This difference shows that the variability in the 2008 population was better explained by this model than the variability in the 2007 population.

The overarching goal of this project is to build a condensed C. album seed germination assay to characterize individual populations to predict seedling emergence patterns in agricultural soils in an effort to decrease interference with crop productivity. The study presented herein is the foundation of this research. The next step will be to examine C. album populations from locations outside of the Midwest to determine if the range of factors examined here are also sufficiently stimulatory for other populations. Once a suitable range of light, temperature, nitrate, water and after-ripening times have been established, the study would progress to analyzing populations collected from agricultural fields in a condensed seed germination assay in an effort to characterize the $\mathrm{C}$. album seedling emergence pattern. The results of this analysis would then be used to better control weed populations by applying herbicides as the most opportune time based on light exposure, temperatures, duration the seed spent in moist soil at cool temperatures, and nitrate and water levels found in the soil from whence the population was collected.

\section{Results}

\subsection{Population}

For the 2007 population, light, temperature, nitrate and after-ripening were significant factors. Water was not found to be a significant factor. The parameters were examined as three-way interactions: light by temperature by after-ripening, light by nitrate by after-ripening and light by temperature by nitrate. The mean square error for the 2007 population was 0.82 .

\subsubsection{Light $\mathrm{x}$ Temperature $\mathrm{x}$ After-ripening Time}

Light stimulated the 2007 C. album population germination but its effects varied with temperature (temp) and after-ripening duration $\left(4^{\circ} \mathrm{C}\right.$, dark, moist; time $\left.\mathrm{AR}_{\mathrm{AR}}\right)$ prior to germination when averaged over water and nitrate levels (Fig. 1). All germination percent means have a standard error of $17 \%$.

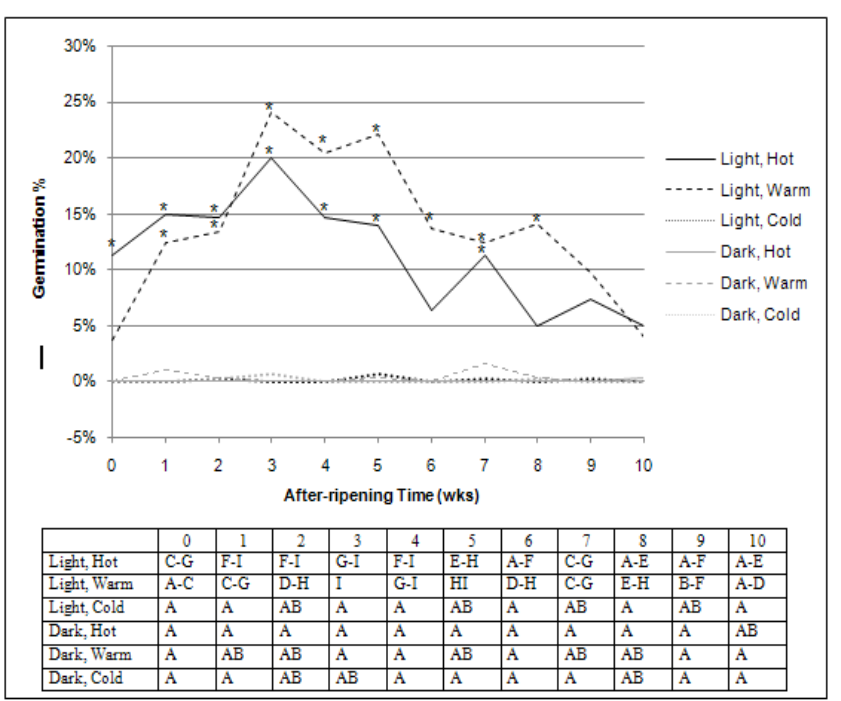

Figure 1. The effects of light, temperature and after-ripening time $\left(4^{\circ} \mathrm{C}\right.$, dark, moist; time $\mathrm{AR}_{\mathrm{AR}}$ ) averaged over water and nitrate levels on 2007 Chenopodium album population seed germination (\%). Top figure: germination percent means for warm or hot with $(*)$ were significantly different from cold at that after-ripening time at the $\mathrm{p}=0.05 \%$ level. Warm and hot were similar at all after-ripening times. Bottom table: germination percent means with the same letter were not significantly different at the $\mathrm{p}=$ $0.05 \%$ level.

Dark. Germination in the dark varied from 0 to $1 \%$ (temp $\left.\mathrm{p}_{\text {cold }}\right), 0$ to $2 \%$ (temp $\left.\mathrm{p}_{\text {warm }}\right)$ or remained at $0 \%$ (temp $\mathrm{phot}_{\text {t }}$ ) and was similar at all time $\mathrm{AR}_{\mathrm{R}}$ at these temperatures (Fig. 1).

Light: among temperatures within after-ripening time. Light-stimulated germination at $15-25^{\circ} \mathrm{C}\left(\right.$ temp $\left._{\text {warm }}\right)$ and $25-35^{\circ} \mathrm{C}\left(\right.$ temp $\left._{\text {hot }}\right)$ were similar at all time AR $_{\text {e }}$ (Fig. 1). Light-stimulated germination at temp ${ }_{\text {warm }}$ was greater at 1-8 weeks and similar at 0 and 9-10 weeks time AR $_{\text {relative to that }}$ at $5-15^{\circ} \mathrm{C}$ (temp cold . Light-stimulated germination at temp $p_{\text {hot }}$ was greater at 0-5 and 7 weeks and similar at 6 and 8-10 weeks time $_{\mathrm{AR}}$ relative to that at temp cold. $_{\text {. }}$

Light: within temperatures among after-ripening times.

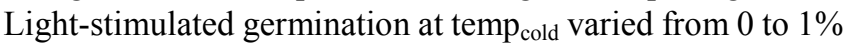
and was similar at all time $\mathrm{AR}_{\mathrm{AR}}$ (Fig. 1). Maximum light-stimulated germination (22-24\%) occurred at temp ${ }_{\text {warm }}$ after 3-5 weeks time ${ }_{\text {AR }}$. Light-stimulated germination at temp $\mathrm{w}_{\text {warm }}$ increased with $0-3$ weeks time ${ }_{\mathrm{AR}}$, then decreased with 3-10 weeks time ${ }_{\mathrm{AR}}$ and was never less than $4 \%$. Light-stimulated germination at temp $\mathrm{pot}_{\mathrm{t}}$ was greater at 3 weeks compared to 6 and 8-10 weeks time AR $_{\text {and }}$ and never less than $5 \%$.

\subsubsection{Light $x$ Nitrate $x$ After-ripening Time}

Light stimulated the 2007 C. album population germination but its effects depended on the presence of nitrate in the water solution and after-ripening duration prior to germination when averaged over temperature and moisture levels (Fig. 2). All germination percent means have a standard error of $14 \%$. 


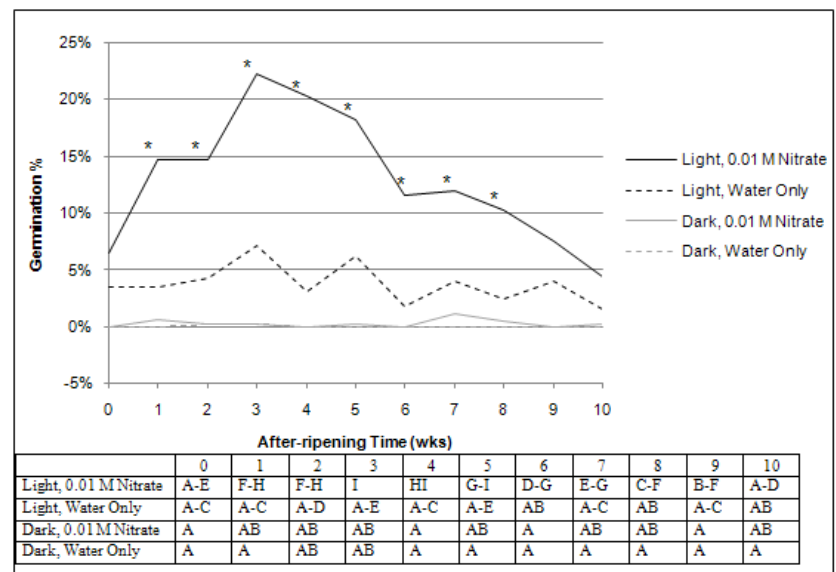

Figure 2. The effects of light, nitrate and after-ripening time averaged over temperature and water levels on 2007 Chenopodium album population seed germination (\%). Top figure: germination percent means for $0.01 \mathrm{M}$ nitrate with $(*)$ were significantly different from water only at that after-ripening time at the $\mathrm{p}=0.05 \%$ level. Bottom table: germination percent means with the same letter were not significantly different at the $\mathrm{p}=$ $0.05 \%$ level.

Dark. Germination in the dark was very low and remained at $0 \%$ (water only) or varied from 0 to $1 \%(0.01 \mathrm{M}$ nitrate) and was similar at all time $\mathrm{AR}_{\mathrm{AR}}$ (Fig. 2).

Light: among nitrate levels within after-ripening time. Light-stimulated germination with $0.01 \mathrm{M}$ nitrate was greater at 1-8 weeks and similar at 0 and 9-10 weeks time AR $_{\mathrm{AR}}$ relative to that in only water within each of those time $_{\mathrm{AR}}$ (Fig. 2).

Light: within nitrate levels among after-ripening times. Light-stimulated germination in only water varied from 2 to $7 \%$ and was similar at all time $\mathrm{AR}_{\mathrm{AR}}$ (Fig. 2). Maximum light-stimulated germination (18-22\%) occurred with $0.01 \mathrm{M}$ nitrate after 3-5 weeks time ${ }_{\mathrm{AR}}$. Light-stimulated germination with $0.01 \mathrm{M}$ nitrate increased with 0-3 weeks time ${ }_{\mathrm{AR}}$, then decreased with 3-10 weeks time $\mathrm{AR}_{\mathrm{AR}}$ and was never less than $4 \%$.

\subsubsection{Light $\mathrm{x}$ Temperature $\mathrm{x}$ Nitrate}

Light stimulated the 2007 C. album population germination but its effects vary with temperature and the presence of nitrate in the water solution when averaged over water quantity and after-ripening duration (Fig. 3). All germination percent means have a standard error of $7.1 \%$.

Dark. Germination in the dark was very low and remained at $0 \%$ (water only) or varied from 0.1 to $0.7 \%(0.01 \mathrm{M}$ nitrate) and was similar at all temperatures (Fig. 3). In the dark, no germination occurred in only water at tempwarm or temphot.

Light: among nitrate levels within temperature. Light-stimulated germination with $0.01 \mathrm{M}$ nitrate was greater at tempwarm and temphot and similar at tempcold relative to that in only water within each of these temperatures (Fig. 3).

Light: within nitrate levels among temperatures. Light-stimulated germination in only water varied from 0.1 to $6.1 \%$ and was similar at tempwarm and temphot, both of which were greater than that at tempcold (Fig. 3). Maximum light-stimulated germination (21.1\%) occurred with $0.01 \mathrm{M}$ nitrate at tempwarm. Light-stimulated germination with 0.01 $\mathrm{M}$ nitrate at tempwarm was greater than that at both tempcold and temphot, while that at temphot was greater than at tempcold.

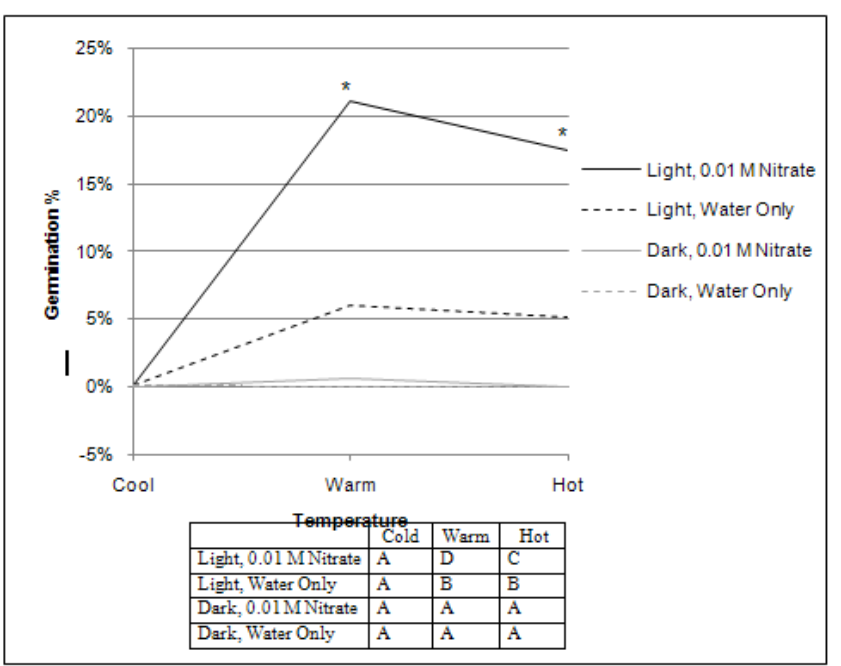

Figure 3. The effects of light, temperature and nitrate averaged over water levels and after-ripening times on 2007 Chenopodium album population seed germination (\%). Top figure: germination percent means for $0.01 \mathrm{M}$ nitrate with $(*)$ were significantly different from only water at that temperature at the $\mathrm{p}=0.05 \%$ level. Bottom table: germination percent means with the same letter were not significantly different at the $p=0.05 \%$ level.

\subsection{Population}

For the 2008 population, light, temperature, nitrate, after-ripening and water were significant. These parameters were examined as four-way interactions: light by temperature by nitrate by water and light by temperature by nitrate by after-ripening. The mean square error for the 2008 population was 0.62 .

\subsubsection{Light $\mathrm{x}$ Temperature $\mathrm{x}$ Nitrate $\mathrm{x}$ Water}

Light stimulated the 2008 C. album population germination but its effects varied with temperature, nitrate and water quantity when averaged over after-ripening duration (Fig. 4). All germination percent means have a standard error of $14 \%$.

Dark. Germination in the dark was very low and varied from 0 to $1 \%$ and was similar at all temperatures, nitrate and water quantities (Fig. 4).

Light: among water and nitrate levels within a temperature. Light-stimulated germination at temp $p_{\text {cold }}$ remained at $0 \%$ and was similar with and without the presence of nitrate at all water quantities (Fig. 4). Within both temp warm $_{\text {and temp }}$ at, light-stimulated germination in the presence of nitrate was similar with the highest water quantities $(1.25,1.00 \mathrm{ml})$ and both were greater than that at $0.75 \mathrm{ml}$ water. In the absence of nitrate, light-stimulated germination within temp $\mathrm{warm}_{\text {and }}$ temp $p_{\text {hot }}$ were similar at all water quantities. Within both temp $\mathrm{warm}_{\text {and }}$ an $\mathrm{p}_{\text {hot, }}$ light-stimulated germination in the 
presence of $0.01 \mathrm{M}$ nitrate was greater than that in only water at all water quantities.

Light: within water and nitrate levels among temperatures. In the presence of nitrate and light, germination at temp ${ }_{w a r m}$ was greater than that at both temp $p_{\text {cold }}$ and temp $p_{\text {hot }}$, while that

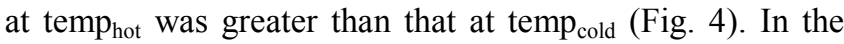
absence of nitrate, light-stimulated germination at temp $\mathrm{warm}_{\mathrm{w}}$ was greater than that at both temp $\mathrm{p}_{\text {cold }}$ and temp $\mathrm{p}_{\text {hot }}$ for all water quantities. Light-stimulated germination in the absence of nitrate was similar at temp cold $_{\text {and temp }}$ for for all water levels.

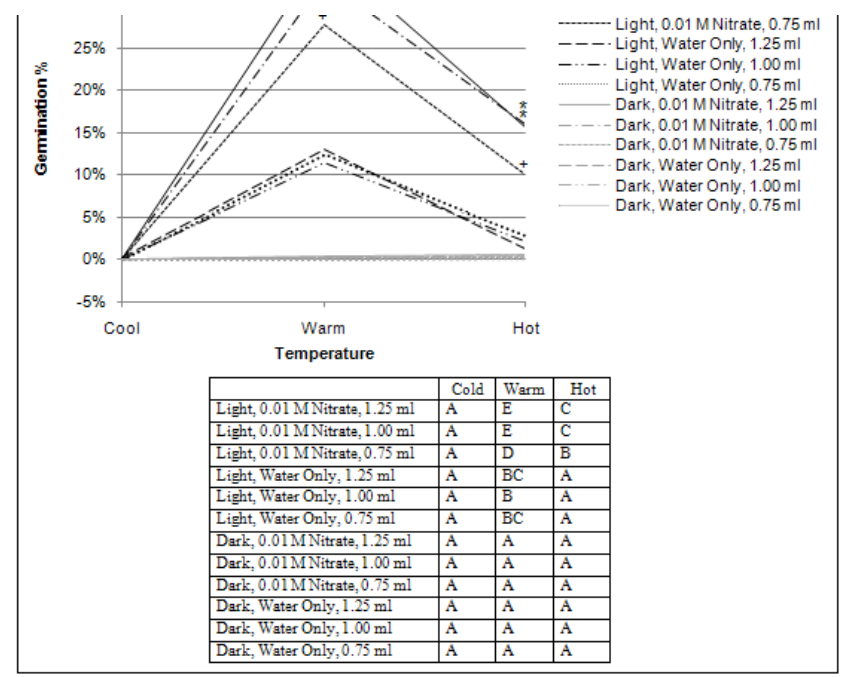

Figure 4. The effects of light, temperature, nitrate and water averaged over after-ripening times on 2008 Chenopodium album population seed germination (\%). Top figure: germination percent means with $(*)$ or $(+)$ were significantly different from all other means at that temperature, those with the same symbol were not significantly different from one another, both criteria at the $\mathrm{p}=0.05 \%$ level. Bottom table: germination percent means with the same letter were not significantly different at the $\mathrm{p}=0.05 \%$ level.

\subsubsection{Light $\mathrm{x}$ Temperature $\mathrm{x}$ Nitrate $\mathrm{x}$ After-ripening Time}

Light stimulated the 2008 C. album population germination but its effects varied with temperature, presence of nitrate and duration of after-ripening time when averaged over water quantity (Fig. 5). All germination percent means have a standard error of $7.5 \%$.

Dark. Germination in the dark was very low and varied from 0 to $1.3 \%$ and was similar at all temperatures, nitrate levels and after-ripening durations (Fig. 5).

Light: among temperature and nitrate levels within after-ripening time. Light-stimulated germination at temp $\mathrm{p}_{\text {warm }}$ with $0.01 \mathrm{M}$ nitrate was greater than that at all other conditions when compared at each time $\mathrm{AR}_{\mathrm{AR}}$ from 1-9 weeks, with maximum germination (50.7\%) at week 5 (Fig. 5). In the light, germination at temp $\mathrm{p}_{\text {warm }}$ with $0.01 \mathrm{M}$ nitrate was greater than that at temp $\mathrm{cold}_{\text {cold }}$ (with or without nitrate) at time $\mathrm{AR}_{\mathrm{AR}}$ 10 weeks. Light-stimulated germination at temp hot $_{\text {with }} 0.01$ $\mathrm{M}$ nitrate was greater than that at temp $\mathrm{p}_{\text {cold }}$ with nitrate and all other temperatures with only water when compared at time $\mathrm{AR}$ 4 weeks. Light-stimulated germination at temp $p_{\text {hot }}$ with 0.01 $\mathrm{M}$ nitrate and temp $\mathrm{warm}_{\text {with }}$ water only was greater than that at temp $p_{\text {cold }}$ with nitrate and all other temperatures with only water when compared at each time $\mathrm{AR}_{\mathrm{AR}} 2-7$ and 2-8 weeks, respectively. In the light, germination at temp $\mathrm{phot}_{\text {with }} 0.01 \mathrm{M}$ nitrate was greater than that at temp $p_{\text {cold }}$ (with and without nitrate) when compared at time $\mathrm{AR}_{\mathrm{R}} 8$ weeks.

Light: within temperature and nitrate levels among after-ripening times. Light-stimulated germination at temp $p_{\text {cold }}$ and temp $p_{\text {hot }}$ with only water and temp $p_{\text {cold }}$ with $0.01 \mathrm{M}$ nitrate varied from 0 to $3.7 \%$ and were similar at all time AR $_{\mathrm{A}}$ (Fig. 5). Light-stimulated germination at temp warm $_{\text {(with and }}$ without $0.01 \mathrm{M}$ nitrate) and at temp $p_{\text {hot }}$ with $0.01 \mathrm{M}$ nitrate increased initially, forming a plateau of higher germination before decreasing within the $0-10$ weeks time $_{\mathrm{AR}}$, although the period of higher germination varied with temperature and nitrate condition. The period of light-stimulated higher germination occurred at time ${ }_{\mathrm{AR}} 2-8$ weeks for temp $\mathrm{p}_{\text {warm }}$ with $0.01 \mathrm{M}$ nitrate, 3-4 weeks for temp ${ }_{\text {warm }}$ with only water, and 2-6 weeks for temp hot with $0.01 \mathrm{M}$ nitrate.

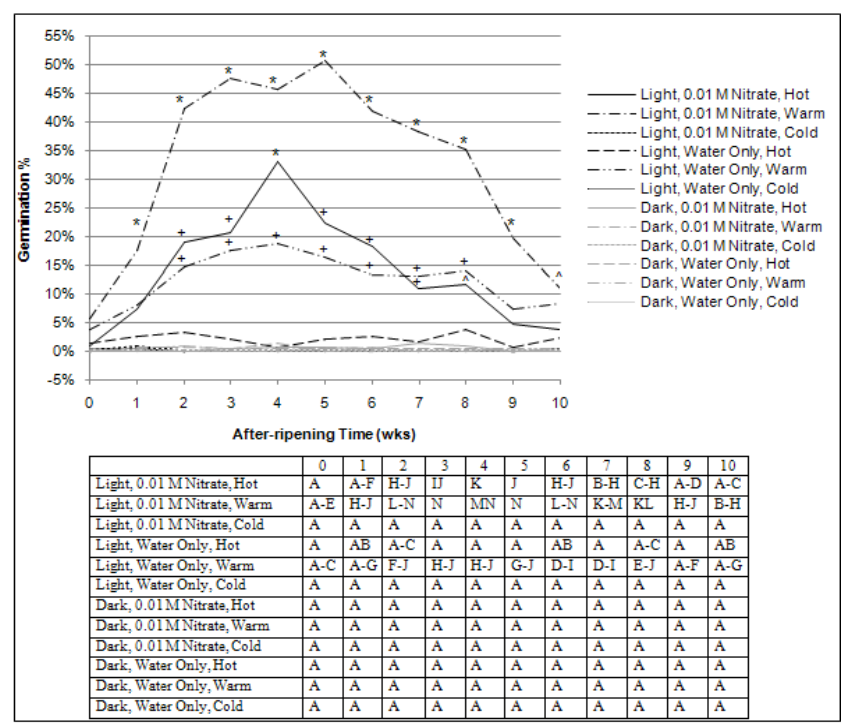

Figure 5. The effects of light, temperature, nitrate and after-ripening time averaged over water quantities on 2008 Chenopodium album population seed germination (\%). Top figure: germination percent means were significantly different from all other means $(*)$; those with $(+)$ were significantly different from cold and hot with only water and cold with nitrate; and those with $\left(^{\wedge}\right)$ were significantly different from cold with and without nitrate; all criteria within an after-ripening time at the $p=0.05 \%$ level. Bottom table: germination percent means with the same letter were not significantly different at the $\mathrm{p}=0.05 \%$ level.

\section{Discussion}

This study agreed with many previously published papers on the germination patterns of Chenopodium album. Germination in the light exceeded that in the dark which supported the findings of Baskin and Baskin (1977), Cumming (1963), Henson (1970), Jursik et al. (2003), Karssen (1967), Moravcova and Dostalek (1989), Vincent and Roberts (1977), Roberts and Benjamin (1979) and Wentland (1965). There was an especially favorable response to light and nitrate applied in combination which had previously been documented by Bouwmeester and 
Karssen (1989, 1993), Henson (1970), Moravcova and Dostalek (1989), Roberts and Benjamin (1979) and Wentland (1965). In the absence of light, germination was not different from zero regardless of nitrate application. These results did not agree with the findings of Saini, Bassi and Spencer (1985a) whom reported higher rates of germination in the dark when seeds were exposed to nitrate. Here, in light with no nitrate, germination occurred at moderate rates and the addition of nitrate stimulated germination further. This illustrated that the combination of light plus nitrate is more effective than either treatment applied individually.

C. album seeds after-ripened in the dark at cool temperatures and in moist conditions have been reported to germinate at a higher rate, particularly when after-ripening is followed by germination in the light with the application of nitrate (Moravcova and Dostalek, 1989; Williams, 1962, 1963; Williams and Harper, 1965; Roberts and Benjamin, 1979; Vincent and Roberts, 1977). These reports were supported by the results of this experiment, where after-ripening at $4{ }^{\circ} \mathrm{C}$ in the dark in moist conditions for approximately 3-5 weeks in the light with nitrate (and at warm temperatures) was the most stimulatory of all conditions investigated. Roberts and Benjamin (1979) postulated that extended after-ripening times may result in reduced germination or induction of secondary dormancy. This hypothesis may explain the decrease in germination rates seen after 7, 8,9 and 10 weeks of after-ripening in the light with nitrate and/or warm to hot temperatures (Fig. 1, 2 and 5). However, Williams (1962) found that C. album seeds after-ripened for both 12 and 52 weeks had similar germination to those after-ripened for 4 weeks, essentially demonstrating no decrease in germination due to extended after-ripening. Future C. album germination studies looking at the effects of extended after-ripening times at one-week intervals would provide further insight into this matter.

The effects of moisture on C. album germination have not been widely examined in previous reports. Based on preliminary studies and those found herein, there seems to be an optimum range of moisture levels which stimulate germination. Having examined levels ranging from 0.5 to 4.0 $\mathrm{ml}$, the optimum water level appears to be approximately 1.25 to $2.0 \mathrm{ml}$ for the vial system used in these experiments (see methods and materials for more information on the vial system).

It was apparent in this study that cold temperatures $\left(5-15^{\circ} \mathrm{C}\right.$, alternating in 12 hour cycles) inhibit germination regardless of light, nitrate and after-ripening (all of which factors would otherwise be providing stimulatory germination effects). Warm $\left(15-25^{\circ} \mathrm{C}\right)$ and hot $\left(35-35^{\circ} \mathrm{C}\right)$ temperatures were effective at promoting germination in the light, especially with the addition of nitrate and 3-5 weeks of after-ripening. This positive interaction among light, nitrate, alternating temperatures and after-ripening was also reported by Vincent and Roberts (1977). The optimal (constant) temperature range for germination of C. album is reportedly between 15 and $25^{\circ} \mathrm{C}$ which agreed with this study which found higher germination rates with alternating temperatures $15-25^{\circ} \mathrm{C}$ relative to $5-15^{\circ} \mathrm{C}$ and $25-35^{\circ} \mathrm{C}$.

\section{REFERENCES}

[1] Baskin, J. M., and C. C. Baskin. 1977. Role of temperature in the germination ecology of three summer annual weeds. Oecologia. 30:377-382.

[2] Baskin, J. M. and C. C. Baskin. 1987. Temperature requirements for after-ripening in buried seeds of four summer annual weeds. Weed Res. 27:385-389.

[3] Bouwmeester, H. J., and C. M. Karssen. 1989. Environmental factors influencing the expression of dormancy patterns in weed seeds. Ann. Bot. 63:113-120.

[4] Bouwmeester, H. J., and C. M. Karssen. 1993. Seasonal periodicity in germination of seeds of Chenopodium album $\mathrm{L}$. Ann. Bot. 72:463-473.

[5] Chu, C. C., R. D. Sweet, and J. L. Ozbun. 1978. Some germination characteristics in common lambsquarters (Chenopodium album). Weed Sci. 26:255-258.

[6] Crocker, W. 1906. Role of seed coats in delayed germination.Contributions from the Hull Botanical Laboratory. LXXXV. Bot. Gaz. 42:265-291.

[7] Cumming, B. G. 1959. Extreme sensitivity of germination and photoperiodic reaction in the genus Chenopodium(tourn.) L. Nature. 184:1044-1045.

[8] Cumming, B. G. 1963. The dependence of germination on photoperiod, light quality, and temperature, in Chenopodium spp. Can. J. Bot. 41:1211-1233.

[9] Dekker, J. and M. Hargrove. 2002. Weedy adaptation in Setaria spp.: V. Effects of gaseous environment on giant foxtail (Setariafaberii R. Hermm.) (Poaceae) seed germination. Am. J. Bot. 89:410-416.

[10] Delorit, R. J. 1970. An illustrated taxonomy manual of weed seeds.Agronomy Publications, River Falls, Wisconsin.p 76.

[11] Fawcett, R. S. and F. W. Slife. 1978. Effects of field applications of nitrate on weed seed germination and dormancy. Weed Sci. 26:594-596.

[12] Gleason, H. A. and A. Cronquist. 1963. Manual of vascular plants of northeastern United States and adjacent Canada. D. Van Nostrand Company, New York, New York. p 274.

[13] Harvey, S. J. and F. Forcella. 1993. Vernal seedling emergence model for common lambsquarters(Chenopodium album). Weed Sci. 41:309-316.

[14] Henson, I. E. 1970. The effects of light, potassium nitrate, and temperature on the germination of Chenopodium album $\mathrm{L}$. Weed Res. 10:27-39.

[15] Holmes, M. G. and H. Smith. 1977a. The function of phytochrome in the natural environment. I. Characterization of daylight for studies in photomorphogenesis and photoperiodism. Photochem.Photobiol. 25:533-538.

[16] Holmes, M. G. and H. Smith. 1977b. The function of 
phytochromein the natural environment. II. The influence of vegetation canopies on the spectral energy distribution of natural daylight. Photochem.Photobiol. 25:539-545.

[17] Holmes, M. G. and H. Smith. 1977c. The function of phytochromein the natural environment. IV. Light quality and plant development. Photochem.Photobiol. 25:551-557.

[18] Jursik, M., J. Soukup, V. Venclova, and J. Holec. 2003. Seed dormancy and germination of Shaggy soldier (GalinsogaciliataBlake.) and Common lambsquarter (Chenopodium album L.). Plant Soil Environ. 49:511-518.

[19] Karssen, C. M. 1967. The light promoted germination of the seeds of Chenopodium album L. I. Theinfluence of the incubation time on quantity and rate of the response to red light.Acta Bot. Neerl.16:156-160.

[20] Karssen, C. M. 1968. The light promoted germination of the seeds of Chenopodium album L. II. Effects of (RS)-Abscisic acid.Acta Bot. Neerl. 17:293-308.

[21] Karssen, C. M. 1970. The light promoted germination of the seeds of Chenopodium album L. V. Dark reactions regulating quantity and rate of the response to red light. Acta Bot. Neerl. 19:187-196.

[22] Moravcova, L. and J. Dostalek. 1989. Contribution to the biology of germination of four species of Chenopodium albumagg. under different conditions. Folia Geobot.Phytotx. 24:431-439.

[23] Morgan, D. C. and H. Smith. 1978. The relationship between phytochrome photoequilibrium and development in light grown Chenopodium album L. Planta. 142:187-193

[24] Morgan, D. C. and H. Smith. 1979. A systematic relationship between phytochrome-controlled development and species habitat, for plant grown in simulated natural radiation. Planta.145:253 258.

[25] Morgan, D. C. and H. Smith. 1981. Control of development in Chenopodium album L. by shadelight: the effect of light quantity (total fluence rate) and light quality (red:far-red ratio). New Phytol. 88:239-248.

[26] Murdoch, A. J., E. H. Roberts, and C. O. Goedert. 1989. A model for germination responses to alternating temperatures. Ann. Bot. 63:97-111.

[27] Roberts, E. H. and S. K. Benjamin. 1979. The interaction of light, nitrate and alternating temperatures on the germination of Chenopodium album, Capsellabersa-pastoris and Poaannuabefore and after chilling. Seed Sci. Technol. 7:379-392.

[28] Saini, H. S., P. K. Bassi, and M. S. Spencer. 1985a. Seed germination in Chenopodium album L.: Relationships between nitrate and the effects of plant hormones. Plant Physiol. 77:940-943.

[29] Saini, H. S., P. K. Bassi, and M. S. Spencer. 1985b. Seed germination in Chenopodium album L.: Further evidence for the dependence of the effects of growth regulators on nitrate availability. Plant Cell Environ. 8:707-711.

[30] Saini, H. S., P. K. Bassi, and M. S. Spencer. 1986. Use of ethylene and nitrate to break seed dormancy of common lambsquarters (Chenopodium album). Weed Sci. 34:502-506.

[31] Smith, H. 2000. Phytochromes and light signal perception by plants - an emerging synthesis. Nature.407:585-591.

[32] Smith, H. and G. C. Whitelam. 1997. The shade avoidance syndrome: multiple responses mediated by multiple phytochromes. Plant Cell Environ. 30:840-844.

[33] Smith, H., J. J. Casal, and G. M. Jackson. 1990. Reflection signals and the perception by phytochrome of the proximity of neighboring vegetation. Plant Cell Environ. 13:73-78.

[34] Vincent, E. M. and E. H. Roberts. 1977. The Interaction of light, nitrate and alternating temperatures in promoting the germination of dormant seeds of common weed species. Seed Sci. Technol. 5:659 670.

[35] Wentland, M. J. 1965. Effects of photoperiod on the seed dormancy of Chenopodium album.Ph.D. Dissertation, University of Wisconsin.

[36] Wiese, A. M. and L. K. Binning. 1987. Calculating the threshold temperature of development for weeds. Weed Sci. 35:177-179.

[37] Williams, J. T. 1963. Biological flora of the British Isles: Chenopodium album L. J. Ecol. 51:711-725.

[38] Williams, J. T. and J. L. Harper. 1965. Seed polymorphism and germination I. The influence of nitrates and low temperature on the germination of Chenopodium album. Weed Res. 5:141-150.

[39] Williams, J. T. 1962. Studies on the biology of weeds with special reference to the genus Chenopodium L. Ph. D. thesis, University of Wales. 